\title{
Experimentos de Design para uma democracia em jogo
}

\section{Design Experiments For a Democracy At Stake}

\author{
COSTARD, Mariana; Doutoranda; Escola Superior de Desenho Industrial (Esdi/UERJ)
}

marianacostard@gmail.com

SECIOSO, Flavia; Mestranda; Escola Superior de Desenho Industrial (Esdi/UERJ)

flaviasecioso@gmail.com

SERPA, Bibiana; Doutoranda; Escola Superior de Desenho Industrial (Esdi/UERJ)

bibianaoserpa@gmail.com

SZANIECKI, Barbara; PhD, Professora Adjunta; Escola Superior de Desenho Industrial (Esdi/UERJ)

dolar.rj@terra.com.br

VENTURA, Liana; Mestranda; Escola Superior de Desenho Industrial (Esdi/UERJ)

liloaventura@gmail.com

\section{Resumo}

Este artigo trata de três experimentos a partir de um jogo enquanto dispositivo de conversação adaptado a diferentes contextos e desenvolvido por pesquisadores do Laboratório de Design e Antropologia (LaDA/Esdi/UERJ). Foi inicialmente criado no âmbito do curso de extensão "Mapapraça-máquina: experimentos de design colaborativo no espaço público", chamado "Jogo dos Verbetes", com o objetivo de estimular o debate sobre conceitos teóricos. Tendo se mostrado uma ferramenta eficiente, foi posteriormente levado para o "Simpósio Imagem, Identidade e Território (SIIT)", para promover o diálogo entre algumas pesquisas realizadas pelo LaDA e o tema proposto pelo seminário. No terceiro momento, foi aplicado numa roda de conversa no Centro de Artes da Maré para pensar suas formas de ocupação e atuação na favela e suas relações com o território. Analisamos o processo do jogo como possibilidade de ampliar um diálogo democrático por meio do design, relacionando bases teóricas para a prática de um design político.

Palavras Chave: codesign; democracia; design anthropology; dispositivos de conversação.

\begin{abstract}
This paper approaches three different experiments using a game as a conversation dispositif developed by researchers from the Laboratory of Design and Anthropology (LaDA/Esdi/UERJ). It was designed to be adapted to different contexts and it was conceived within the scope of the outreach course Map-square-machine: collaborative design experiments in the public space. Named Entry Games, its purpose was to stimulate a broader debate on theoretical concepts. So far, it has proved to be an efficient tool and it was later taken to the Image, Identity and Territory Symposium (SIIT) to encourage exchange among researchers from the network in a creative way. Finally, the researchers used it in an activity at Maré Arts Center to support a discussion on NGOs' actions inside the favela and how they relate to the territory. We intend to analyse the game process as a possibility to expand a democratic dialogue by means of design, linking theoretical
\end{abstract}


bases to a practice of a political project.

Keywords: codesign; democracy; design anthropology; conversation dispositifs.

\section{Introdução}

Este artigo trata de alguns experimentos realizados no âmbito do Laboratório de Design e Antropologia da Escola Superior de Desenho Industrial da Universidade Estadual do Rio de Janeiro (LaDA/Esdi/UERJ), no cruzamento de diferentes pesquisas que buscam explorar o design como agente político na construção coletiva de imaginários democráticos e espaços comuns de agenciamentos e singularidades heterogêneas. A partir de um jogo que funciona como "dispositivo de conversação" (Anastassakis \& Szaniecki, 2016), adaptado a diferentes contextos, analisamos o potencial democrático do design em agregar pessoas em torno de assuntos comuns e promover diálogo entre ideias e interesses potencialmente diversos ou mesmo controversos.

Baseado em abordagens como Design Anthropology e Codesign, partimos de um design como modo de investigação que não apenas procura refletir criticamente sobre seus possíveis papeis frente aos desafios sociais contemporâneos, mas deseja engajar-se ativamente nos contextos com os quais trabalha.

Com uma breve descrição, podemos dizer que o Design Anthropology (Gun e Donovan, 2012; Smith et al, 2016; Ingold, 2013; Anastassakis, 2015) é um campo interdisciplinar que conjuga múltiplas práticas e saberes em busca de um envolvimento prático com o contexto de pesquisa. Assim, assumimos um posicionamento intervencionista por meio do desenvolvimento de ferramentas experimentais mediadoras que provoquem diálogos através da prática, para a cocriação de alternativas possíveis para o futuro.

Já o Codesign contribui com um arcabouço de métodos, ferramentas e técnicas de engajamento entre designers e não designers na exploração coletiva de ideias e visões de futuro em processos de design. Por meio de atividades de visualização, imaginação, experimentação e reflexão contínua, essa abordagem explora o potencial democrático da participação, podendo assumir um papel importante na democratização da democracia enquanto um processo contínuo de fazer e desfazer alinhamentos e conexões socio-materiais. Assim, essa abordagem visa preparar as condições necessárias para que questões controversas emerjam e possam ser discutidas de modo amplo e democrático (Binder et al., 2015).

É no seio deste contexto que emerge um conceito desenvolvido a partir da palavra thing (coisa) entendida como assembleia para mediar conflitos e tomar decisões coletivas (Latour, 2014; Binder et al, 2011): design things (coisas de design) assumem o sentido de "conjuntos complexos de questões contraditórias" (Latour, 2014) que passam a desenvolver um papel importante no campo do design. Em oposição ao objeto como artefato material e fato consumado, as "coisas de design" podem ser representações de "questões de interesse"1 assim como meios para gerar novos agenciamentos socio-materiais a partir da articulação de condições sociopolíticas (Latour,

\footnotetext{
1 Tradução do termo Matters of concern em Latour, Bruno. Um Prometeu cauteloso? Alguns passos rumo a uma filosofia do design (com especial atenção a Peter Slotedijk). In: Agitprop: revista brasileira de design, São Paulo, v. 6, n. 58, jul/ago 2014.
} 
2005). Trata-se, portanto, de espaços de diálogo e discussão entre diferentes pontos de vista; de ferramentas e técnicas para articular pessoas com o objetivo de analisar problemas e, juntas, imaginar possibilidades; de representação dos interesses numa linguagem comum de modo a facilitar as mediações e o compartilhamento de questões e visões; de um papel de mediação de uma pesquisa com objetivos relacionais abertos a interpretações (Bjögvinsson et al, 2012; Koskinen, 2011).

Argumentamos em favor de práticas que envolvam a "participação micropolítica na produção do espaço/tempo", na qual os "dispositivos de conversação" propostos sejam capazes de moldar a (re)produção de relações sociais e espaciais. Diferentemente de um exercício que orienta a participação nos processos de design visando a construção de consensos ou a estabilização de um conjunto particular de relações sociais, buscamos um design político que explora o dissenso e as possibilidades de uma democracia agonística plural (Keshavarz e Mazé, 2013).

Nesse sentido, associamos a ideia de "dispositivos de conversação" (Anastassakis \& Szaniecki, 2016) à de design things para qualificar o jogo aqui analisado enquanto experimento de pesquisa e diálogo público no cenário urbano. Articulando o conceito de "dispositivo" de Foucault com o de "conversação" como uma construção compartilhada de discursos possíveis, propomos o uso de artefatos de visualização para construir processos abertos de engajamento e imaginação coletiva sobre visões possíveis a respeito das questões relativas ao espaço urbano.

O jogo aqui apresentado surge da reflexão sobre possíveis formas de ação de um design político que toma a democracia como um processo de disputa contínuo e não como um estado ou objetivo fixo. Na prática de "dispositivos de conversação" e design things associadas ao Design Anthropology, defendemos o conflito não apenas como necessário, mas produtivo. Assim, foram realizadas três diferentes experiências com o jogo, cada uma com um público diferente e uma temática específica a cada caso. Ainda que aplicados em ambientes distintos, as práticas do jogo criaram espaços de disputa, diferença e dissenso para revelar e confrontar relações através de objetos e processos, identificando discursos, práticas e bases para novas questões (DiSalvo, 2010).

\section{0 jogo}

Tendo conceituado as abordagens do design que embasam a nossa pesquisa e prática, apresentamos o jogo desenvolvido por pesquisadores do LaDA como procedimento metodológico do design enquanto modo de investigação crítica e coletiva. Com influência do Codesign dinamarquês, utilizamos os "jogos exploratórios de design" (Brandt et al, 2006) para promover engajamento em processos participativos, imaginar futuros possíveis e engendrar sentidos coletivos. "Em linhas gerais, o objetivo de um jogo exploratório de design é propiciar um ambiente de aprendizado coletivo múltiplo, seguro e lúdico, acionando mecanismos motivadores para evocar a criatividade e facilitar a relação entre os atores envolvidos" (Szaniecki et al, 2017).

O jogo é composto por cartas que contêm imagens ou textos dispostos em peças hexagonais, com quantidade variável para cada situação, em função do contexto, do conteúdo e do número de jogadores. Antes de começar a partida, as peças são distribuídas entre os participantes. O jogo é iniciado por uma peça-chave, uma carta hexagonal que representa a provocação central e norteadora dos debates da partida. A partir do disparador inicial entendido como o dispositivo que aciona debates - os jogadores, um a um, devem criar conexões entre as cartas dispostas na mesa e as suas, construindo aos poucos uma estrutura conceitual 
(tabuleiro) sobre o tema proposto. A forma como essa estrutura se configura depende das conexões feitas entre as cartas e dos argumentos levantados pelos jogadores para justificar tais relações. Portanto, a cada nova jogada, esse tabuleiro pode constituir formatos e conteúdos diferentes. Visto que as cartas são distribuídas aleatoriamente, o jogo também se coloca como um desafio intelectual e criativo. Isso quer dizer que, na medida em que o jogador não escolhe o seu conjunto de cartas, ele é impelido a pensar critica e criativamente sobre as possíveis relações entre as cartas que têm disponíveis em mãos e as cartas dispostas no tabuleiro.

Exemplo: o Jogador 1 deve escolher uma de suas cartas e conectar em um dos lados da peça-chave. Em seguida, ele deve argumentar sobre sua escolha, articulando ideias com a carta escolhida e a provocação central, seguindo a dinâmica de diálogo que o jogo busca despertar. Por sua vez, o Jogador 2 , ao escolher sua carta, pode optar entre conectar à peça-chave ou à carta do Jogador 1, ou ainda em ambas as cartas simultaneamente. As jogadas seguintes seguem a mesma dinâmica podendo associar a carta jogada aos lados disponíveis das cartas dispostas na mesa. Não é necessário que a carta a ser jogada tenha relação com a última, de forma que é possível retomar pontos já discutidos a partir de uma nova conexão.

É importante ressaltar que apesar de ser um jogo que convoca ao debate, não se trata de um jogo que implica na concorrência entre os participantes. Não existe resposta certa ou errada e, portanto, não existem vencedores ao final. Não há duração predefinida, o final do jogo é decidido pelos jogadores, quando se sentem satisfeitos com as reflexões promovidas.

Vejamos a seguir os diferentes contextos em que o jogo foi utilizado como investigação coletiva, tendo sido criado inicialmente no âmbito do curso de extensão "Mapa-praça-máquina", depois adaptado ao "Simpósio Imagem, Identidade e Território (SIIT)" e como ferramenta de conversa no Centro de Artes da Maré. Cada situação tinha seus objetivos próprios e gerou dinâmicas e resultados diferentes.

\section{Mapa-Praça-Máquina: experimentos de design colaborativo no espaço público}

O curso de natureza teórico-prática intitulado "Mapa-Praça-Máquina: experiência de design colaborativo no espaço público" foi realizado como curso de extensão da Escola Superior de Desenho Industrial (Esdi/UERJ) em parceria com o Centro Municipal de Arte Hélio Oiticica (CMAHO), através da sua Plataforma de Emergência. Aberto ao público e concebido de forma cocriada entre coordenador e pós-graduandos, o curso teve como proposta experimentações de práticas colaborativas no espaço público, mais especificamente na Praça Tiradentes, situada na região central da cidade do Rio de Janeiro. A união desses três elementos - mapa, praça e máquina - pretendia evocar e incitar o encontro, proposital ou ao acaso, de heterogeneidades: o mapa como mote de conversação e captura de informação, a praça como o potencial local desses processos e a máquina, já presente ou ainda por ser construída, como aquela que vem atualizar essa potência. Nessa mistura, buscamos investigar o que faz funcionar os encontros e o que produz engajamento, entendendo o design como uma importante ferramenta política de articulação entre esses campos.

O desafio inicial foi criar um ambiente no qual todos os participantes compartilhassem uma base teórica comum, respeitando as diferentes perspectivas de cada um. O curso foi organizado didaticamente em torno de quatro eixos principais: Design e pesquisa; Espaço; Imagem; e Sociedade. Tais temas orientaram os conteúdos, a natureza das atividades de intervenção propostas aos alunos e as metodologias sugeridas para realizá-las. 
A partir dessa sistematização, foi desenvolvido o "Jogo dos Verbetes". Com quarenta e duas cartas que materializam ideias e conceitos dos verbetes, o jogo foi aplicado com o objetivo de trabalhar, de forma introdutória e sucinta, o conteúdo necessário ao andamento das atividades, preservando o caráter crítico e reflexivo da experiência sem que leituras extensivas prévias fossem necessárias. Criado como um "dispositivo de conversação", o "Jogo dos Verbetes" procurou, a partir de uma provocação central, despertar o diálogo entre seus jogadores por meio da exposição, contextualização, embasamento e debate das opiniões de todos.

Nesse processo, os envolvidos foram encorajados a estranhar e/ou (re)conhecer lugares, pessoas e, neste caso, identificar as dinâmicas que a coletividade da Praça Tiradentes manifestava, como vivências e utilizações, expectativas e realidades, políticas e necessidades. $O$ intuito era especular realidades e esboçar intervenções pelas quais a sociedade pudesse repensar e reativar suas próprias relações físicas e afetivas com o espaço.

Neste sentido, o "Jogo dos Verbetes" funcionou como um conjunto metodológico para viabilizar a discussão de questões comuns aos jogadores, trazendo ainda visões e conceitos de outros contextos. Dessa forma, a articulação de saberes, opiniões e visões de mundo - em suas pluralidades de origem e natureza - é o ponto central para as potencialidades desse jogo.

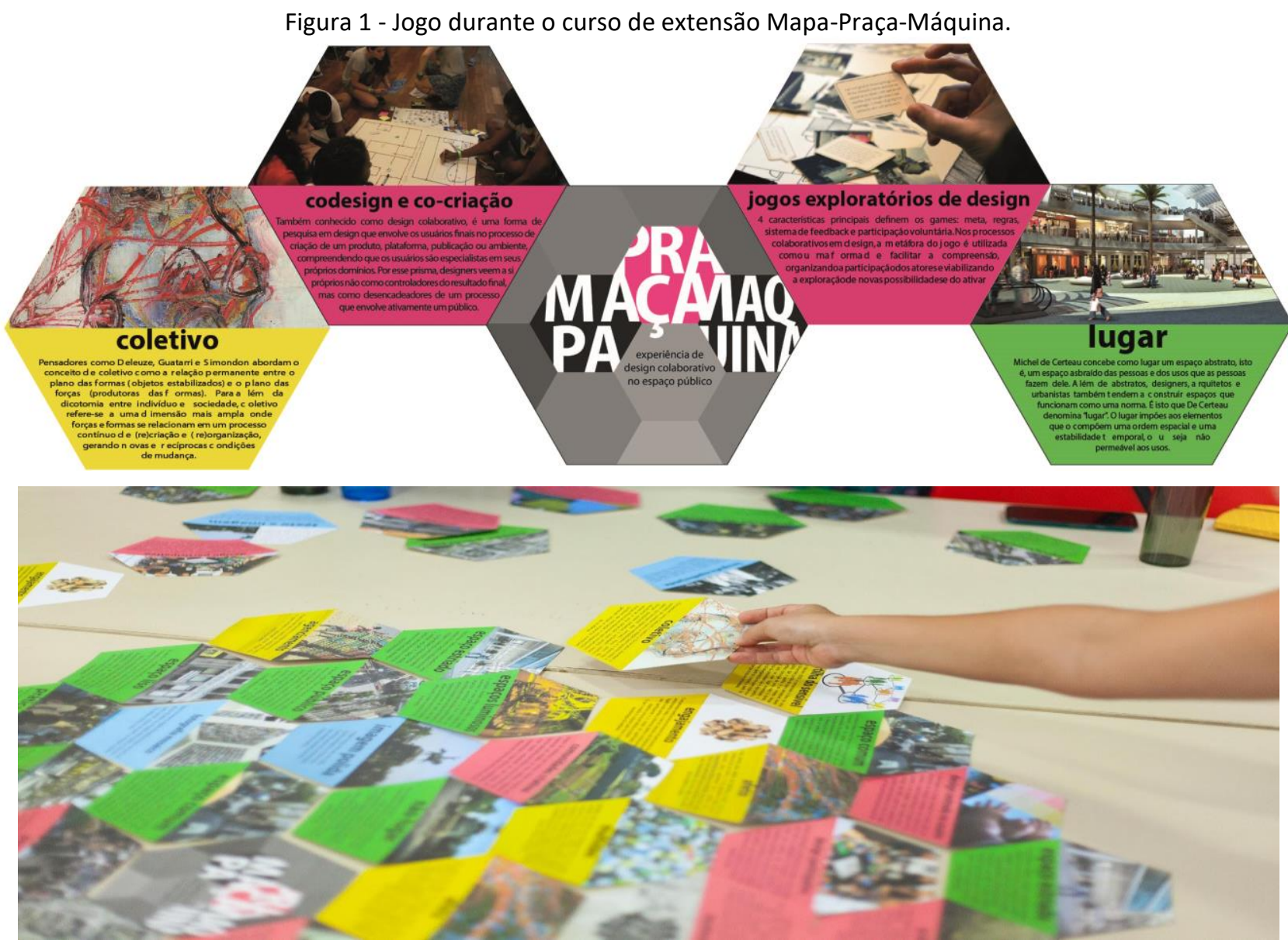

Fonte: LaDA (2016) 


\section{Simpósio Imagem e Identidade e Território (SIIT) - E agora América Latina?}

Um novo experimento do jogo foi vivenciado no 70 Simpósio Imagem e Identidade e Território (SIIT), realizado em outubro de 2017 na Faculdade de Arquitetura da Universidade Federal do Rio Grande do Sul (UFRGS). Com o tema "E agora, América Latina? Práticas Insurgentes no Mosaico Territorial", o simpósio propôs um olhar voltado diretamente para o continente latino-americano, que se expressa como um mosaico de alteridades em diálogo, mas também em disputa.

Convidado a participar do SIIT, o Laboratório de Design e Antropologia (LaDA) optou por uma atividade coletiva que apresentasse e colocasse em debate as pesquisas realizadas no laboratório. Retomamos o jogo desenvolvido no curso Mapa-Praça-Máquina e recriamos cartas para a situação específica. Cada pesquisador propôs questões relacionadas a sua pesquisa que dialogassem de alguma forma com o tema do Simpósio. As cartas então foram recriadas contendo afirmações e perguntas provocativas, além de imagens geradoras de associações com o conteúdo de modo a fortalecer a participação dos demais pesquisadores e incitar o debate sobre os temas. Desta forma, diversas pesquisas realizadas pelo LaDA foram expostas por meio do jogo com o objetivo de tecer relações com outros grupos de pesquisa e colher reflexões elaboradas pelo público presente, acadêmicos mas não apenas.

As regras foram sutilmente alteradas a fim de estimular mais disputa e agregar um caráter mais divertido ao jogo. Foram criados dois novos elementos - a "treta" e o "textão" - inspirados nas gírias das redes sociais e no atual contexto de turbulência política. Estes elementos, em forma de adesivos de cores diferentes, funcionaram como intervenções durante as jogadas. Quando um jogador discordava de uma carta lançada ou do argumento levantado para a colocação da mesma, ele colava o adesivo "treta" sobre essa mesma carta e argumentava sua oposição. A "treta" foi amplamente usada pelos jogadores e se mostrou um recurso eficiente para incitar o debate, trazendo maior participação e amplitude nas discussões do jogo. Já o adesivo "textão", poderia ser aplicado por qualquer participante para cessar a fala de algum jogador, caso fosse considerada muito extensa. Esta intervenção foi criada com o objetivo de deixar o jogo mais dinâmico e não reservar tempo demais para uma fala individual. Qualquer um que se sentisse incomodado poderia intervir para que o jogo prosseguisse.

Se "treta" foi a ferramenta utilizada para debater os conteúdos, "textão" foi aquela necessária para debater a própria forma da democracia, isto é, suas próprias regras centralizadoras. Durante esta realização do jogo, as regras foram constantemente tensionadas e não por acaso. O recurso ao "textão" não procurava censurar as falas e sim modular seu uso, oferecendo a todos os participantes a oportunidade de se expressar, oportunidade essa que tem faltado nos espaços e tempos da política de representação. 


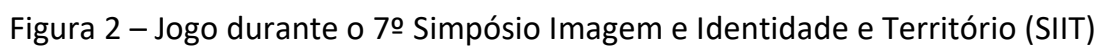

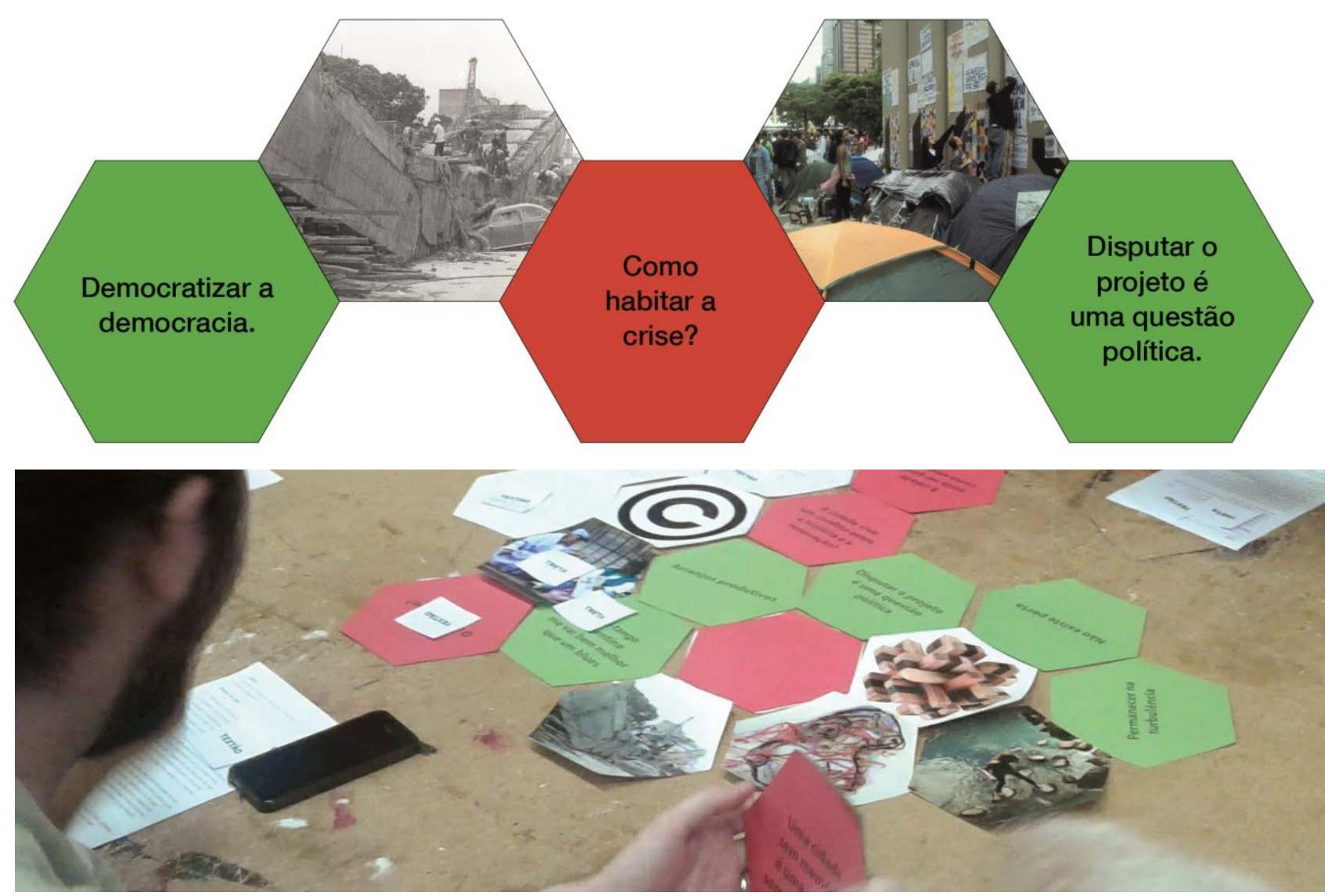

Fonte: LaDA (2017)

\section{Jogo Puxa-papo - Centro de Artes da Maré}

O terceiro experimento do jogo foi aplicado numa roda de conversa para pensar formas de ocupação do Centro de Artes da Maré e as relações com o território. A convite da pesquisadora Bruna Montuori (FAU/USP), o jogo foi aplicado como uma ação seguida de uma oficina de construção de mobiliário, ministrada pela própria pesquisadora, no Centro de Artes da Maré, no Rio de Janeiro. A ação, realizada em novembro de 2017, foi vinculada às atividades da Bienal de Arquitetura de São Paulo 2017.

O Centro de Artes da Maré (CAM) é um projeto da Redes da Maré, uma organização da sociedade civil que se dedica à promoção de uma rede de desenvolvimento sustentável, no maior conjunto de favelas do Rio de Janeiro, o Complexo da Maré. É um espaço de encontro de saberes, de circulação e produção de práticas que estimulam novas formas de apreensão do mundo, desenvolvendo expressões artísticas múltiplas que, em geral, são pouco acessíveis aos setores sociais populares.

O jogo desta vez recebeu o nome de "Puxa-Papo" como forma de reforçar a ideia de um dispositivo que desperta o diálogo. Esta terceira edição foi desenvolvida no intuito de sensibilizar o público quanto às questões relacionadas a espaço, lugar, território, identidade, arte e design. Novas cartas foram criadas, preservando o caráter crítico e reflexivo das experiências anteriores. 0 conteúdo das cartas buscou articular questões teóricas e frases provocativas que estimulassem 
percepções sobre o território, a construção coletiva do espaço, além de trazer reflexões sobre arte e design. $O$ desafio final era ativar as relações físicas e afetivas dos participantes com aquele lugar para que seguissem sensibilizados na produção de peças de mobiliário na oficina, que seria dada em seguida.

O tom acadêmico das versões anteriores foi substituído por uma linguagem mais informal, com o intuito de facilitar o engajamento de um público heterogêneo formado por moradores e pessoas que trabalham ou frequentam o Centro de Artes da Maré.

Repetimos o recurso das etiquetas "treta" e "textão", que se mostraram novamente eficientes para enriquecer a participação e articulação de ideias. As jogadas "treta" e "textão", nesse contexto, provaram ser articuladores democráticos. Ao lançar a etiqueta "textão" o jogador procurava, mesmo que somente através do olhar, aprovação dos demais, se a maioria não achasse que era textão, a jogada continuava sem interrupções. Mesmo sem ter sido estabelecido enquanto regra, essa jogada acabava dependendo mais de um acordo coletivo de certa forma consensual. O marcador "treta" teve caráter mais individual, mas ainda assim, muitos jogadores embarcavam na treta do companheiro, apontando problemas do discurso ou ratificando pontos expostos. Com diversas questões democráticas emergindo, o jogo durou aproximadamente 60 minutos, deixando os participantes satisfeitos com as reflexões promovidas.

Os participantes puderam tecer relações, de oposição ou afinidade, entre os mesmos e as suas próprias vivências na comunidade, frente às linhas de forças ou fragilidades que o atravessam. Entretanto, percebemos que o conteúdo das cartas estavam muito abrangentes, com assuntos diversificados que deixaram a conversa, apesar de profícua, pouco direcionada para o fim proposto da oficina. Contudo, os participantes acharam a experiência enriquecedora pois discutiram diversos assuntos e puderam entender mais sobre o que é design e sua amplitude de atuação. Todos falaram sobre como o jogo serviu de estímulo para uma conversa que pode chegar a diversas reflexões e não necessariamente a soluções.

Figura 3 - Jogo realizado no Centro de Artes da Maré

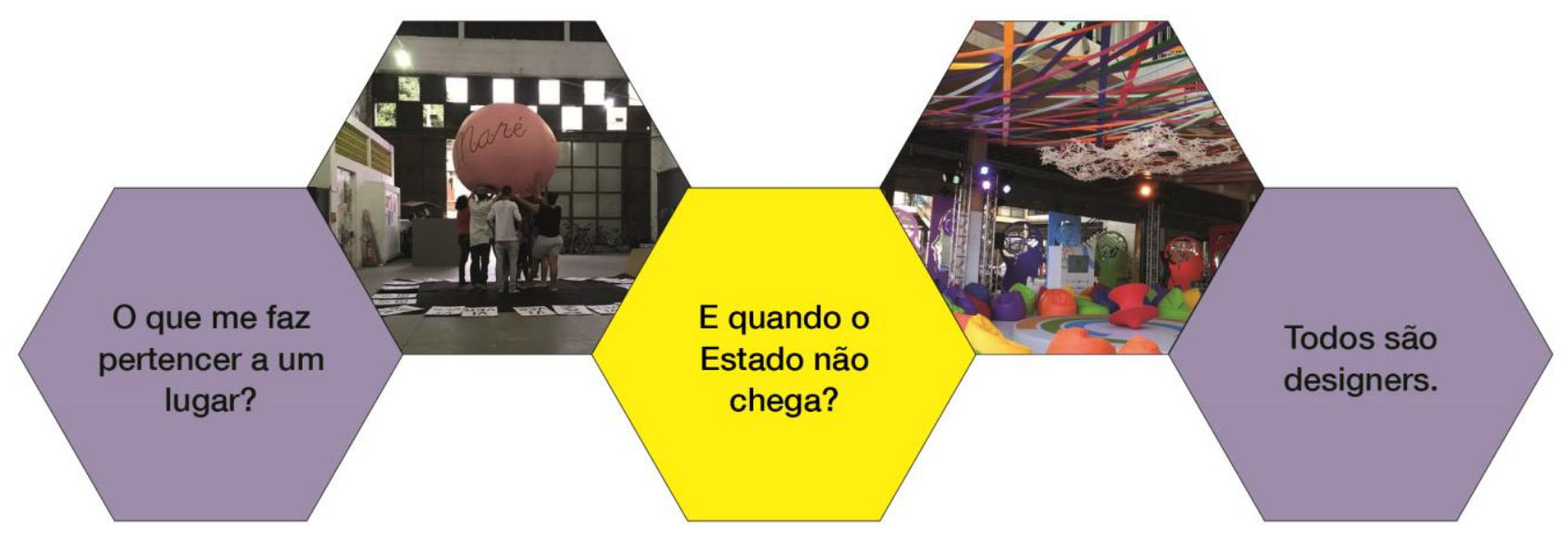






Fonte: LaDA (2017)

\section{Articulações e Considerações Finais}

Ao desenvolvermos jogos, tínhamos como objetivo a criação de um ambiente provocador que instigasse os participantes a debater suas ideias mas que fosse, ao mesmo tempo, suficientemente lúdico para que não gerasse oposições ou proibições em termos de pensamentos e práticas.

O jogo se mostrou uma potente ferramenta, capaz de levar os participantes a tecer reflexões a partir de conexões e entrelaçamentos inusitados ou pouco óbvios, que emergem a partir do diálogo não ensaiado ou roteirizado comum a entrevistas, mesmo semi-estruturadas. A conversa se constrói a partir das cartas, onde, mais interessante do que o que nelas está escrito, é o que não está escrito. A resposta de um afeta a fala do outro, em convergências e divergências e, assim, ideias que não surgiriam quando se está sozinho, são despertadas nas trocas em grupo.

A materialidade visual das cartas, em formas e cores estimuladoras de interação, conduzem a um gestual de jogadas em sequências dinâmicas que despertam a sensibilidade para a elaboração de questões, a curiosidade do que vem a seguir e a capacidade da coletividade de se produzir entre consensos e dissensos. Nossa abordagem, apoiada no Design Anthropology (Gun e Donovan, 2012; Smith et al, 2016; Ingold, 2013; Anastassakis, 2015) e, também no Design as Politics (Fry, 2010) levanta questões sobre a política de pesquisa em design. As abordagens de pesquisa baseadas em práticas, como as exemplificadas aqui, desenvolvem a teoria no contexto da prática de design, através da ativa construção de conceitos teóricos trazidos à prática, bem como a geração de novos conceitos a partir da prática. Nisso, argumentamos que o desafio não é apenas entender e incorporar teorias crítico-políticas externas, mas construir um arcabouço intelectual para o design com base em seus próprios modos de operação. Esta questão vem sendo abordada por DiSalvo em suas considerações sobre a democracia agonística e sobre o papel que um Adversarial Design pode exercer para estimulá-la. Nas características aqui apresentadas, reconhecemos a capacidade do design ir além da mera aplicação das ciências sociais ou mera ferramenta para uso das ciências sociais (antropologia, sociologia e ciências políticas entre outros) para se afirmar como campo produtor de um tipo de conhecimento, que é pensamento e prática ao mesmo tempo.

Por outro lado, reconhecemos que o dispositivo possui alguns desafios a serem 13을 Congresso Brasileiro de Pesquisa e Desenvolvimento em Design, Univille, Joinville (SC) 
trabalhados e superados. Um deles é pensar em como podemos minimizar efeitos indutivos devido a pré-formatação de questões e provocações propostos pelas cartas. Para que o jogo seja realmente democrático, não apenas em relação à participação, mas também no que se refere à escolha e elaboração de seu conteúdo, seria preciso equilibrar a própria formulação do jogo entre mediadores e participantes. Compreendemos que projetar com as partes interessadas pode ser bastante desafiador ainda que os objetivos sociais comuns estejam estabelecidos ou vistos como razoavelmente acessíveis. $O$ desafio realmente exigente é projetar onde tal consenso não pode ser visto à priori. É interessante entender que o jogo atua também como uma plataforma de um espaço público agonístico - não necessariamente para resolver conflitos, mas para lidar construtivamente com desentendimentos já postos (Bjögvinsson et al, 2012). Desta forma, o Codesign do jogo já seria uma prática útil para a definição das questões contraditórias (Latour, 2014) e de tomada de decisões coletivas. Nesse sentido, os limites e possibilidades do design participativo têm sido efetivamente repensados em prol de uma maior colaboração por meio de Codesign e por meio de experimentos democráticos de design (Binder et al, 2015) dos quais nossos lúdicos "dispositivos de conversação" (Anastassakis \& Szaniecki, 2016) fazem parte.

A heterogeneidade dos grupos que compuseram as jogadas também trouxe reflexões. É preciso atentar-se às hierarquias que se colocam nos grupos quando se propõe processo de participação e dissenso. Os marcadores "treta" e "textão", por exemplo, foram ótimos articuladores democráticos para debate de conteúdo em dissenso e para autogestão do tempo de jogo. No entanto, mesmo diante da dinâmica descontraída e prevista pelas regras, percebeu-se cautela no uso dessas etiquetas em ambientes marcados por hierarquias. Dessa forma, é necessário repensar estratégias que promovam horizontalidade na participação, ao mesmo tempo que se propõe o dissenso e a democracia.

Outra questão levantada a partir desses três experimentos é a sua falta de encaminhamentos. O jogo é capaz de criar um framework conceitual amplo sobre questões trabalhadas, mas ainda não conseguimos pensar em formas suficientemente efetivas de registrar os debates, de reorganizar e retornar às ideias e reflexões levantadas pelos participantes e de, a partir desses dois momentos, elaborar planos de ação com eles. Como este é um dispositivo em constante atualização e reinvenção, a ideia é seguir as pistas deixadas em cada vivência para continuarmos lançando novas experimentações capazes de corresponder aos desafios do momento. Trata-se de desafios para os projetos de design e para o próprio projeto de democracia tal como os recentes movimentos globais indicam (Graeber, 2015).

De formas e com objetivos distintos, a prática dos jogos se mostraram efetivas na promoção do diálogo sem pressupor um consenso ao longo do processo ou mesmo ao final. Entendemos que, embora restritos em sua territorialidade e em seus efeitos imediatos, os experimentos democráticos de design aqui apresentados pretendem contribuir para os processos de democratização da democracia em curso, para um design político na possibilidade de uma democracia agonística plural. 


\section{Referências}

Anastassakis, Zoy. Projeções, provocações e especulações entre design e antropologia no centro da cidade do Rio de Janeiro. In: Ferro, Ligia; Raposo, Otavio; Gonçalves, Renata Sá. (Orgs.). Expressões artísticas: etnografia e criatividade em espaços atlânticos. 1ed. Rio de Janeiro: Mauad X : Faperj, v. , p. 209-228, 2015.

Anastassakis, Zoy.; Szaniecki, Barbara. Conversation Dispositifs: Towards a Transdisciplinary Design Anthropological Approach. In: Design Anthropological Futures. London: Bloomsbury, 2016. Binder, Thomas, et al. Design Things. The MIT Press, 2011.

Binder, Thomas, et al. Democratic design experiments: between parliament and laboratory. CoDesign 11 (3-4), p. 152-165, 2015.

Bjögvinsson, Erling, Pelle Ehn, and Per-Anders Hillgren. Design things and design thinking: Contemporary participatory design challenges. Design Issues 28.3, p. 101-116, 2012.

Brandt, Eva. Designing Exploratory Design Games: a framework for participation in participatory design? Proceedings Participatory Design Conference, 2006.

DiSalvo, Carl. Design, democracy and agonistic pluralism. Proceedings of the design research society conference. 2010.

DiSalvo, Carlo. Adversarial Design. Cambridge e Londres: The MIT Press, 2015.

Fry, Tony. Design as Politics. Londres: Bloombsbury, 2010.

Graeber, David. Um Projeto de Democracia. Uma história, uma crise, um movimento. São Paulo: Paz e Terra, 2015.

Gunn, Wendy; Donovan, Jared. (Eds.) Design and Anthropology: Anthropological studies of creativity and perception. London: Ashgate, 2012.

Ingold, Tim. Making: Anthropology, Archaeology, Art and Architecture. Abingdon: Routledge, 2013.

Keshavarz, M; Mazé, R. Design and dissensus: framing and staging participation in design research. Design Philosophy Papers 11 (1), 2013.

Koskinen, Ilpo, Zimmerman, John, Binder, Thomas, Redstrom, Johan, \& Wensveen, Stephan. Design things: model scenarios, prototypes. in Design research through practice: From the lab, field, and showroom. Elsevier, 2011.

Latour, Bruno. From realpolitik to dingpolitik. Making things public: Atmospheres of democracy. Karlsruhe and Cambridge, MA: Centre for Art and Media Karlsruhe and MIT Press, p. 14-44, 2005.

Latour, Bruno. Um Prometeu cauteloso? Alguns passos rumo a uma filosofia do design (com especial atenção a Peter Slotedijk). In: Agitprop: revista brasileira de design, São Paulo, v. 6, n. 58, jul/ago 2014.

Smith, Rachel Charlotte, et al. Design Anthropological Futures, 2016.

Szaniecki, Barbara et al. Mapa-Praça-Máquina: experimentos de design no espaço público. Rio de Janeiro, 2017. 